\title{
A reputação do departamento de marketing nas instituições comunitárias de ensino superior brasileiras e sua influência na orientação para o mercado
}

\section{The reputation of the marketing department in community teaching institutions and their influencemarket orientation}

\author{
RENATO LAURENTINO SILVA \\ ALEXANDRE LUZZI LAS CASAS
}

\section{RESUMO}

Este artigo buscou averiguar os fatores que influenciam a reputação do Departamento de Marketing (DM) nas Instituições Comunitárias de Ensino Superior (ICES), assim como se essa reputação influencia na orientação ao mercado dessas instituições. Este assunto é relevante, uma vez que o ambiente competitivo do mercado educacional exige que os departamentos de marketing das ICES sejam atuantes e orientados para o mercado, acompanhando as mudanças e agindo diante das ameaças e oportunidades que surgem no setor. A reputação do departamento de marketing influencia no nível de atuação de uma instituição para enfrentar os constantes desafios. A pesquisa foi do tipo quantitativa-descritiva, via questionário estruturado enviado eletronicamente. Os resultados demonstraram que A Reputação do DM está no ponto médio da escala e que o grau de Conhecimento de marketing do Reitor/Mantenedor e o nível de Responsabilidade do DM são seus principais influenciadores. Por meio de uma adaptação da escala MARKOR, verificou-se que a orientação ao mercado das ICES também está no ponto médio da escala. O modelo estatístico

* Pontifícia Universidade Católica de São Paulo. renato.laurentino@gmail.com .

**alascasas@terra.com.br. 
demonstrou que a reputação do DM influencia positivamente na orientação de mercado e que também pode trazer muitos benefícios para as ICES. Por fim, constatou-se que o apoio da alta gestão é fundamental para que o DM tenha uma atuação mais colaborativa e eficaz na organização.

Palavras-chave: Departamento de Marketing. Marketing Educacional. Universidades Comunitárias. Orientação ao Mercado.

\section{AbStract}

This article sought to ascertain the factors influencing the Marketing Department's (MD) reputation in Community Institutions of Higher Education (CIHE), as well as whether this reputation influences the market orientation of these institutions. This issue is relevant, since the competitive environment of the educational market requires the marketing departments of CIHE have to be active and market oriented, following the changes and acting in the face of the threats and opportunities that arise in the sector. The reputation of the marketing department influences the level of performance of an institution to face the constant challenges. The research was of the quantitative-descriptive type, via a structured questionnaire and was sent electronically. The results demonstrated that MD Reputation is at the midpoint of the scale and that the knowledge of the Rector/ Maintainer has about marketing and the MD's Responsibility level are its main influencers. By adapting the MARKOR scale, it has been found that the market orientation of CIHE is also at the midpoint of the scale. The statistical model has shown that MD's reputation positively influences market orientation and it can also bring many benefits to CIHE. Finally, it was verified that the support of the top management is fundamental for the MD to have a more collaborative and effective action in the organization.

Key-words: Marketing Department. Educational Marketing. Community Universities. Market Orientation.

\section{INTRODUÇão}

Apesar do crescimento do setor educacional (ENSINO SUPERIOR, 2015), ainda persiste nas IES a distorcida visão de que educação não deve ser gerenciada por profissionais "de mercado", mas 
por educadores acadêmicos e pedagogos (NUNES et al., 2008). Para Meyer Jr. e Murphy (2003), as universidades formam profissionais e são dirigidas por amadores, dado que a maioria é gerida por professores que não são formados para serem gestores, dificultando a implantação de uma gestão profissional. A concorrência no setor educacional é acirrada entre as instituições comunitárias, e com a entrada de grandes grupos de investidores no mercado, além do surgimento de novas formas de ensino, como o Ensino a Distância (EAD), tornou-se ainda mais competitiva. As instituições sentiram a necessidade de profissionalizar-se, contratando colaboradores especializados, com conhecimento e experiência em suas atividades especificas. Uma dessas atividades é a de captação e retenção de alunos, geralmente sob a responsabilidade do Departamento de Marketing (DM) a quem cabe elaborar planos e gerenciar a execução das ações definidas. No entanto, frequentemente, encontram-se obstáculos para sua implantação, como a resistência de alguns setores das instituições por sentirem-se ameaçados pelo fortalecimento da função de marketing, ou mesmo, por conservadorismo. No entanto, Philip Kotler (1995), um dos pioneiros a escrever sobre o marketing educacional, mencionou que não há nada de prejudicial ou antiético orientar a gestão de uma instituição de ensino pelo marketing, ao contrário, poderá haver benefícios. Franco (2014) ressalta que uma instituição orientada para o mercado minimiza os riscos de investimento e também combate melhor a evasão dos alunos, assim como, colabora com a fidelização, uma vez que as diretrizes apresentadas nessa orientação trazem uma visão, não só das IES, mas também do mercado em que elas atuam. Na orientação pelo marketing o DM exerce um papel estratégico, pois é o responsável por trazer para a organização as informações de mercado relevantes para o negócio. Segundo Gök et al. (2015) um DM com boa reputação pode melhorar a lucratividade da organização, bem como, conseguir clientes mais satisfeitos e leais. Entretanto, a influência do DM nas organizações tem diminuído (WEBSTER et al., 2005; HOMBURG et al. 2015).

Dessa forma buscou-se nesse estudo identificar como as instituições comunitárias de ensino superior (ICES) estão organizando seu departamento de marketing, bem como, entender os principiais fatores de influência na reputação do DM. Buscou-se também ve- 
rificar o grau de orientação de mercado dessas ICES, bem como se ela sofre alguma influência em função do grau de reputação do DM.

O interesse nas instituições comunitárias surgiu pela constatação da necessidade de profissionalização no setor, como também na redução do número de alunos em diferentes cursos, em grande parte motivada pela crise e nas mudanças estruturais do mercado brasileiro, havendo necessidade de atuação mercadológica. Adicionalmente, os pesquisadores atuam no setor há muitos anos.

Este estudo se justifica pelas contribuições, tanto para a academia como para o setor. Para o setor permitirá as instituições balizarem suas atividades com as demais IES, e adaptar suas atividades para tornarem seus Departamentos de Marketing mais respeitáveis e consequentemente, influenciar nas atividades orientadas ao mercado para a obtenção de melhores resultados.

Por fim, passaram-se vinte anos do início das reformas educacionais que mudaram o cenário da educação superior brasileira. É possível afirmar que elas consolidaram um mercado educacional em que há disputa entre as IES de qualquer organização acadêmica pela captação de mais alunos e/ou alunos melhores preparados, assim como, pela retenção dos atuais alunos e também pela conversão destes em estudantes de pós-graduação.

Este estudo também traz contribuições para academia. Muitas pesquisas têm discutido a influência do DM dentro das organizações (ANDERSON, 1982; WIND e ROBERTSON, 1983; DAY, 1992; VARADARAJAN, 1992; WEBSTER, MALTER e GANESAN, 2003; SHETH e SISODIA, 2005; WEBSTER et al, 2005; HOMBURG et al, 2015), entretanto, nenhum deles discute esta influência do DM nas IES. Assim, a contribuição deste trabalho é inédita tanto em âmbito nacional quanto internacional, de modo que os resultados obtidos ampliarão os estudos relacionados ao DM. Portanto, a principal contribuição teórica deste estudo é a de discutir a influência de um Departamento de Marketing na orientação estratégica das ICES.

\section{O DEPARTAMENTO DE MARKETING DENTRO DAS ORGANIZAÇõES}

Os departamentos de marketing surgiram no início dos anos 50 como uma evolução do departamento de vendas que, nos anos 20 e 30, agregavam atividades como propaganda, promoção de 
vendas e pesquisa. $\mathrm{O}$ crescimento dessas atividades e o acirramento da concorrência geraram a necessidade de maior especialização a fim de obter maior entendimento sobre as necessidades e desejos dos consumidores e garantir novas formas de comercialização. A chamada "era do marketing" coloca o foco das organizações sob os anseios dos clientes, e satisfazê-los é a meta. Desse modo, todas as atividades de um DM devem relacionar-se com as de outros departamentos da empresa, como finanças, recursos humanos, produção, vendas entre outras. Como o processo de comercialização envolve todas as áreas de uma empresa, logo, todos devem ter consciência dos objetivos e buscar alcançá-los. Essas interações acabam gerando muitos conflitos de interesses e insatisfação entre os departamentos. Assim, muitas vezes, o papel do DM dentro da empresa é questionado e confundido com as atividades de vendas.

Pupo e Botelho (2011) verificaram que a gestão de marketing organizada em um departamento é algo novo e que ainda está se estabelecendo nas IES. Porém, a maior parte das ações de marketing ainda é utilizada para anunciar os processos seletivos e não como ferramenta de pesquisa ou para colaborar no desenvolvimento de novos cursos, estudos de demanda, produção de conteúdo e geração de valor para a marca. Demonstraram também que, apesar de conhecerem (os dirigentes) muitas métricas de marketing, essas estão em evolução, pois ainda são usadas de forma simples e, muitas vezes, de maneira informal, ou seja, sem um painel de controle de marketing, demonstrando assim a pouca importância que é dada à gestão do marketing nas instituições de ensino. Essa realidade valoriza a afirmação de Yanaze (2011) de que, normalmente, os departamentos de marketing são departamentos de serviços de marketing.

Turpin (2012) sugere que o diretor de marketing de uma empresa seja substituído por um diretor de clientes. A este caberia identificar quem são os clientes, o que querem e suas tendências, e usar essas informações para influenciar os debates dentro da empresa na fabricação de produtos e precificação. Para Kotler (2013), esse diretor de clientes, sugerido por Turpin (2012), não estaria fazendo nada de diferente do que deveria ser feito por um bom diretor de marketing. A quem caber garantir a integração dos quatros "pês" do marketing (produto, preço, praça, promoção) em uma empresa. No 
entanto, em estudo mais recente, o próprio Kotler (2014) assemelha o diretor de marketing - CMO (Chief Marketing Officer) ao diretor de clientes - CCO (Chief Client Officer).

Assim, esta pesquisa também buscou identificar a organização dos DM nas Instituições Comunitárias de Ensino Superior (ICES).

\section{A InlFuÊnCiado departamento de MARKETing NAS ORGANIZAÇõES}

Em alguns estudos verificou-se que o DM tem perdido influência dentro das organizações ao longo dos tempos (ANDERSON, 1982; WIND e ROBERTSON, 1983; DAY, 1992; VARADARAJAN, 1992; WEBSTER, MALTER e GANESAN, 2003; SHETH e SISODIA, 2005; WEBSTER et al., 2005; HOMBURG et al., 2015). De modo geral, as razões encontradas são as seguintes: i) a maioria dos diretores de marketing não está realmente imersa em atividades de marketing, pois eles se concentram mais em comunicação do que em produto e preço; ii) os diretores financeiros se tornaram mais poderosos e assumiram o controle da variável preço em função dos tempos difíceis e, por conta disso, são mais propensos a ocupar o cargo de diretor executivo, dando menos atenção ao diretor de marketing; iii) muitas vezes o impacto do marketing na empresa é difícil de medir, logo, o orçamento dessa área tem maior probabilidade de ser cortado em tempos difíceis e; iv) ninguém tem idéia clara do que é marketing, ao passo que a maioria das pessoas entende no que implica a área de produção ou a área de finanças dentro da organização. A falta de prestação de contas de marketing reduz a satisfação do diretor executivo da empresa com o DM, logo, o menor apoio da alta gerência limita, ainda mais, a influência desse departamento dentro da empresa.

O estudo de Homburg (2015) demonstrou que a influência do DM contribui significativamente tanto para o desempenho do relacionamento com o cliente quanto para o desempenho financeiro da empresa. O departamento de vendas apresentou significância sobre o relacionamento com o cliente, porém, curiosamente, o mesmo não é verdade quanto ao desempenho financeiro. Os resultados da pesquisa também não encontraram relacionamento significante entre o desempenho do relacionamento com o cliente com qualquer departamento. 
Feng, Morgan e Rego (2015), em um estudo longitudinal, analisaram o poder do DM em empresas norte-americanas entre os anos de 1993 e 2008 e o impacto deste sobre o desempenho da organização e observaram que, em geral, o poder do DM aumentou durante esse período. Os estudos também demonstram que um DM mais forte aumenta o retorno total de longo prazo para os acionistas e também exerce um efeito positivo sobre o retorno sobre os ativos (ROA) no curto prazo.

As investigações de Gök et al. (2015) fornecem fortes evidências de que um respeitável DM é necessário para se conseguir clientes mais satisfeitos e leais, melhorar a lucratividade, aumentar a participação de mercado e conquistar novos clientes. Um DM com boa reputação também pode exercer influência dentro da organização, o que afeta positivamente o desempenho dos negócios. Pode ainda denotar uma cultura de marketing proeminente e fortalecer uma orientação para o cliente ou para o mercado dentro da empresa, o que também deve conduzir positivamente os resultados desta.

Um departamento respeitável também pode servir para promover uma melhor progressão profissional para os gestores de marketing e pavimentar o caminho para as funções estratégicas em altos escalões. Evidencia-se que a reputação do DM está positivamente ligada ao desempenho do mercado, independentemente do tipo de estratégia. Por conseguinte, pode-se argumentar que a reputação do DM é fundamental para o desempenho do mercado de qualquer empresa, independentemente da estratégia genérica perseguida (GÖK et al., 2015, p. 375, tradução do autor).

O DM deve buscar garantir o apoio da alta gerência e, neste caso, aumentar a responsabilidade do marketing pode ser benéfico (O'SULLIVAN e ABELA, 2007) e esse apoio pode aumentar a influência do DM (WEBSTER, 2005). Essa influência é maior em empresas cujos diretores executivos têm experiência ou formação em marketing (HOMBURG et al., 1999). Todavia, isso tem diminuído (VERHOEF e LEEFLANG, 2009).

Para Homburg et al. (2015), o DM pode revitalizar sua posição dentro da empresa se puder demonstrar o valor de seus programas. Um possível caminho seria a contratação de pessoas que tenham competência em decisões estratégicas e questões de preço, pois são 
áreas fundamentais para o sucesso da organização e a influência do setor é menor. No entanto, Pupo e Botelho (2011) verificaram que o retorno do investimento (ROI) das ações de marketing não está entre as métricas mais comuns na gestão do marketing educacional. Nas instituições de ensino superior brasileiras, o que se observa é que muitos gestores ainda não dão a devida importância ao marketing e às ferramentas de gestão, assim como os professores e coordenadores de curso ainda não entendem o que é marketing e para o que serve. Com isso, as ações da área ficam prejudicadas, já que o marketing não faz parte da cultura da universidade (GOMES, SILVEIRA e DE SOUZA, 2013).

\section{A REPUTAÇÃo NAS ORGANIZAÇõES E O MARKETING}

Partindo da literatura da sociologia, os pesquisadores organizacionais definem a reputação, ou o status de uma entidade como algo socialmente construído, intersubjetivamente acordado e aceito, ordenando ou classificando indivíduos, grupos, organizações ou atividades em um sistema social. Trata-se de um tipo particular de feedback recebido por uma organização a partir de julgamentos das partes interessadas quanto à sua credibilidade, favorabilidade e atratividade. Esses julgamentos são construídos a partir da avaliação das ações passadas da organização, perspectivas futuras, posição na rede de relacionamento, assim como pela capacidade de entregar resultados de valor e a capacidade de atender as expectativas dos stakeholders (SHRUM e WUTHONOW, 1988; WHETTEN e MACKEY, 2002; LANGE, LEE e DAI, 2011;HUBERMAN, LOCH e ÖNÇULER, 2004; WASHINGTON e ZAJAC, 2005).Sendo o departamento uma subunidade de uma organização ele deve buscar o apoio das outras unidades para sobreviver produzindo algo de valor para o meio de atuação delas (THOMPSON, 1967; PFEIFER e SALANCIK, 1978; TSUI, 1990). Ao produzir algo de valor, a subunidade será vista ou julgada favoravelmente por seus stakeholders, e isso aumentará as possibilidades de sua sobrevivência. Walsh, Beatty e Shiu (2009) apontam que quanto mais favorável for a estimada entidade, mais positivo será o impacto das atitudes, ações e comportamento dela. A reputação organizacional mais elevada de uma unidade leva à inclusão desta nas atividades-chave da empresa e ao respeito dos outros departamentos 
(KAHN, 2005). Dessa forma, a reputação do DM depende do quanto ele é respeitado pelos demais departamentos. Estar bem posicionado nessa hierarquia de status é crucial para que o DM consiga atrair melhores talentos e melhores orçamentos e, por conseguinte, coordenar as suas atividades interfuncionais com mais harmonia, efetividade e melhor eficácia, contribuindo, assim, para um nível melhor de orientação para o marketing (KOTLER e KELLER, 2006). A reputação é um recurso crítico para o departamento de marketing, sinalizando sua proeminência, credibilidade e avanço dentro da organização.

\section{A ORIENTAÇÃo PARA O MERCAdo}

Os estudos sobre orientação de mercado existem desde o início dos anos 60. No entanto, esse termo se destacou na literatura no final dos anos 80 com Shapiro (1988) e início dos anos 90 com os trabalhos de Kohli e Jaworski (1993; 1990), Narver e Slater (1990), Deng e Dart (1994) e Deshpandé, Farley e Webster (1993).

Para Kohli e Jaworski (1990, p. 6), um dos autores mais citados nesse assunto, a orientação para o mercado é "a geração de toda inteligência de mercado da organização referente às necessidades atuais e futuras dos consumidores, disseminação dessa inteligência em todos os departamentos e a resposta de toda organização a esta".

Pode-se afirmar que a orientação de mercado provém da estrutura conceitual do marketing, uma vez que possui o foco central no cliente e também no mercado.

Todavia, Kohli e Jaworski (1990) defendem que o termo Orientação para o Mercado seja mais propicio e eficaz do que a Orientação para Marketing, por três razões: i) a orientação para o mercado esclarece que o constructo não é exclusivamente uma preocupação da função de marketing, mas de uma variedade de departamentos que participam na geração de inteligência de mercado, divulgando -o e realizando ações em resposta a ele; ii) o rótulo de «orientação para o mercado» é menos politicamente carregado na medida em que não insufla a importância da função de marketing em uma organização e; iii) o rótulo chama a atenção para os mercados (que incluem os clientes e as forças que os afetam), o que é consistente com a «gestão dos mercados» proposta mais ampla para abordar os paradigmas adotados à época. 
Para Kaur e Gupta (2010) as probabilidades de desenvolver perspectivas em níveis de gestão são maiores na orientação de mercado do que nas funções de marketing.

Franco (2014) aponta algumas características que são comuns em diversos estudos sobre o tema: orientação para o cliente, coleta de informações; coordenação interfuncional das atividades de marketing e capacidade de resposta aos clientes.

Muitos estudos empíricos relacionando o desempenho organizacional e a orientação para o mercado foi realizada no contexto das organizações brasileiras e de modo geral encontrou-se uma relação positiva dessa orientação com o desempenho das empresas (MENNA 2001; SILVA, DAMACENA e MELO 2002; ANTONI, DAMACENA e LEZANA 2004; SAMPAIO, PERIN e HENRIQSON 2004; PERIN e SAMPAIO 2004; CHRISTINO, 2011; FRANCO, 2014). Destacam-se aqui os trabalhos de Antoni, Damacena e Lezana (2004) e Franco (2014) que aplicaram uma versão modificada da escala MARKOR a instituições de ensino superior e relacionaram a orientação para o mercado com o desempenho organizacional. Esta escala é a mais aplicada nos estudos que mensuram a orientação ao mercado e foi desenvolvida por Kohli e Jaworski (1993). A avaliação por essa escala se dá em três aspectos: capacidade de gerar informação, de disseminar informação e de responder ao mercado. O estudo de Franco (2014) demonstra que tanto as universidades públicas quanto as privadas têm visão sobre o que seja a orientação para o mercado. No entanto, a maioria das IES pesquisadas não apresenta indícios de orientação para o mercado.

\section{DESENVOLVIMENTO DAS HIPÓTESES}

De acordo com Creswell (2007), as hipóteses quantitativas são previsões que o pesquisador faz sobre as relações esperadas entre as variáveis. As hipóteses aqui apresentadas basearam-se no estudo de Gök et al. (2015), que avaliou a reputação do DM nas organizações; no estudo de Verhoef e Leeflang (2009), que buscou entender a influência do DM nas empresas; e no estudo de Homburg et al. (1999), que investigou a influência do marketing nas empresas. As hipóteses relacionadas à orientação para o mercado fundaramse, principalmente, no trabalho de Kohli e Jaworski (1993), que 
apresenta a escala MARKOR desenvolvida para avaliar o grau de orientação para o mercado das organizações e também no trabalho de Franco (2014), que fez uma adaptação dessa escala e aplicou em Instituições de Ensino Superior.

A estrutura de variáveis seguiu o modelo conceitual de Gök et al. (2015), com as devidas adaptações para o presente estudo, conforme ilustrado na Figura 1.

Figura 1- Estrutura de Variáveis e Constructos para a Elaboração do Questionário

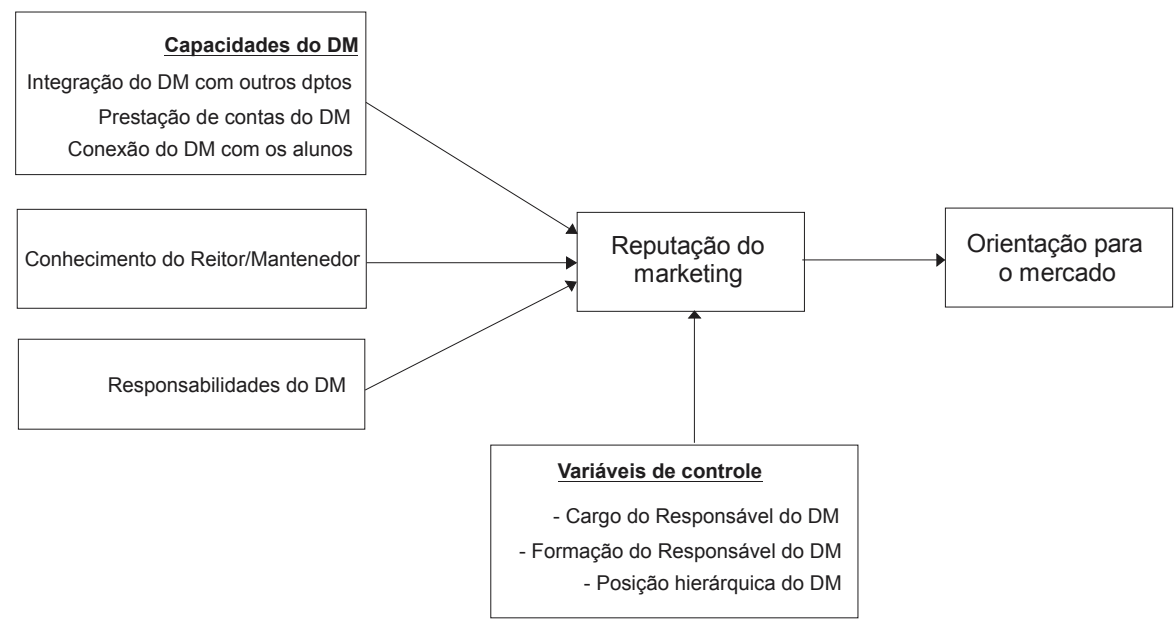

Elaborado pelos autores, adaptado de Gök et al., 2015

A variável dependente central é a Reputação do DM. Como variáveis independentes, atribuímos as (I) Capacidades do DM que incluem: i) Integração do DM com outros departamentos; ii) Prestação de contas do DM; iii) Conexão do DM com os alunos; (II) Conhecimento de Marketing do reitor/mantenedor e (III) as Responsabilidades do DM. A orientação para o mercado foi mantida nesse modelo como variável dependente, uma vez que um dos objetivos dessa investigação é saber se a OM sofre alguma influência da variável dependente central. 
Entende-se que em uma empresa, cada função ou departamento exerce um impacto sobre a satisfação do cliente. Logo, as atividades de marketing devem estar coordenadas com finanças, operações e outras áreas da empresa, a fim de atender ao cliente (YANAZE, 2011). Para isso, a estrutura de marketing da empresa deve dar condições para o DM interagir com todos os setores dela para construir uma relação de respeito e reciprocidade, melhorando a eficácia de seus planos.

O marketing deve estar estruturado em nível de gestão e exercer um forte papel de influência na empresa. Para tanto, o DM da organização deve estar estruturado com pessoas qualificadas e capazes de executar bem suas funções, a fim de garantir uma boa reputação do departamento e, por conseguinte, conseguir melhores resultados (GÖK et al., 2015). Assim, considerando o contexto dos tópicos anteriormente apresentados formulam-se as primeiras hipóteses:

$\mathrm{H}_{1(\mathrm{a})}$ : A orientação para o mercado das ICES está no ponto médio da escala.

$\mathrm{H}_{1(\mathrm{~b})}$ : A reputação do Departamento de Marketing está positivamente relacionada à orientação de mercado das ICES.

\section{CAPACIDADES DOS DEPARTAMENTOS DE MARKETING DAS ICES}

O estudo de Gök et al. (2015) apresenta resultados de trabalhos que definem a capacidade organizacional como a habilidade que uma organização tem para executar um conjunto coordenado de tarefas, usando os seus recursos organizacionais para alcançar um resultado final particular. Também identifica que diversos estudos sobre reputação apontam as capacidades e as competências de uma entidade como determinantes para se auferir reputação. Nesse estudo serão replicadas algumas variáveis testadas no trabalho de Gök et al. (2015): prestação de contas, conexão com clientes e integração com outros departamentos. Eles verificaram que as duas primeiras influenciam positivamente a reputação do marketing, por essa razão optou-se por testá-las nesse estudo.

\section{Prestação de Contas do dePARTAMENTo de MARKeTing}

Em muitas organizações, o DM é percebido como um custo e não como um investimento (VERHOEF e LEEFLANG, 2009). A 
falta de habilidade, muitas vezes observada, dos profissionais de marketing para comunicar sua influência nos resultados da empresa é vista como a principal razão pela redução do prestígio do DM dentro das empresas (GRUCA e REGO, 2005; LEHMANN, 2004 apud HOMBURG et al., 2015). Essa falta de prestação de contas reduz a satisfação da alta administração com o departamento (O'SULLIVAN e ABELA, 2007). Por conseguinte, ter menos apoio dos executivos limita a influência do DM. Homburg et al. (2015) identificaram que o departamento de vendas é que está se beneficiando dessa redução de influência do DM, isto porque vendas é a função primária que gera receita. Logo, resultados podem ser medidos em curto prazo, por exemplo, o crescimento das vendas. O DM irá perder influência para qualquer departamento que melhor for capaz de apresentar os impactos dos seus resultados (LEHMANN, 2004 apud HOMBURG et al.,2015). Uma das formas de reverter essa situação é o DM recrutar pessoas que sejam competentes nas áreas de estratégia e cálculos financeiros. Ambas as áreas são altamente relevantes para os resultados da empresa e o marketing tem perdido influência nelas nos últimos 15 anos (HOMBURG et al., 2015). Considerando os pontos aqui apresentados, propõe-se uma nova hipótese.

$\mathrm{H}_{2}$ : A capacidade de prestar contas do Departamento de Marketing das ICES está positivamente relacionada à sua reputação na instituição.

\section{ConeXÃo COM CLIENTES E POTENCIAIS CLIENTES}

De acordo com o diretor executivo do Sindicato das Mantenedoras do Ensino Superior - Semesp, a evasão no ensino superior é uma ameaça à saúde financeira das IES privadas e a tendência é que metade dos estudantes não conclua a faculdade (ENSINO SUPERIOR, 2015). A principal fonte de receita das instituições de ensino superior, no Brasil, advém das mensalidades pagas pelos alunos, logo, são eles os principais clientes de uma IES. O papel de um diretor de marketing como membro da alta administração é defender os interesses do cliente (KOTLER e ARMSTRONG, 2014). Entender e prever as necessidades dos consumidores melhor do que a concorrência e, efetivamente ofertá-las aos clientes, resultará em vantagem competitiva (GÖK et al., 2015). A orientação para o 
mercado coloca o interesse do cliente em primeiro lugar, sem excluir os interesses dos proprietários (DESHPANDÉ, FARLEY e WEBSTER, 1993). A empresa deve ser mais rápida que os seus concorrentes na criação, na entrega e na comunicação de um valor superior (na visão do cliente) aos seus mercados-alvo escolhidos. A orientação para o marketing consiste em encontrar os produtos/serviços certos para os seus clientes e não mais encontrar clientes certos para os seus produtos ou serviços. Nas IES, cada vez mais a retenção tem sido motivo de preocupação, tanto quanto a captação de novos alunos. Assim, a próxima hipótese sugere que:

$\mathrm{H}_{3}$ : A capacidade do Departamento de Marketing de se conectar com os clientes (alunos e potenciais alunos) das ICES está positivamente relacionada à sua reputação na instituição.

\section{INTEGRAÇÃo DO DEPARTAMENTO DE MARKETING COM OUTROS SETORES}

Sob a orientação de marketing, todos os departamentos devem trabalhar em conjunto para satisfazer as necessidades e expectativas dos clientes e o DM tem de fazer que isso aconteça. Quando os departamentos trabalham juntos, com objetivos comuns, o marketing é mais efetivo (YANAZE, 2011). Os mesmos autores afirmam que as relações interdepartamentais costumam ser conflituosas e caracterizadas por desconfianças e rivalidades. Isso em decorrência das diferenças de opinião quanto ao que é melhor para a empresa. Por causa de sua experiência com o gerenciamento de relações interorganizacionais, o DM pode ser, idealmente, posicionado para integrar e mediar as relações de rede interna, a fim de aumentar a sua proeminência funcional nas organizações modernas (ACHROL e KOTLER 1999). A comunicação, negociação e colaboração com outros setores da instituição são determinantes para uma reputação positiva (YU e CABLE, 2011 apud GÖK et al., 2015). Ancorado nessas premissas, a hipótese que emerge é:

$\mathrm{H}_{4}$ : A cooperação do Departamento de Marketing das ICES com os outros departamentos (acadêmicos e administrativos) está positivamente relacionada à sua reputação na instituição. 


\section{O CONHECIMENTO DE MARKETING DO CEO}

A presença de um CMO (Chief Marketing Officer), ou diretor de marketing, entre os executivos da organização deve ser relacionada a contingenciar as incertezas e complexidades nos aspectos críticos de domínio do marketing (NATH e MAHAJAN, 2008). O DM tem sido posto em dúvida em algumas empresas (HOMBURG et al.,2015) e uma das razões notada é a falta de habilidade para comunicar a contribuição dos seus investimentos para os resultados da empresa (HOMBURG et al., 2015). Essa falta de habilidade pode impactar na redução de orçamento para o DM (KUMAR e SHAH, 2009; TAVASSOLI e SORESCU, 2014; WEBSTER et al., 2005). Esses cortes reduzem o potencial de ação do departamento e, por conseguinte, a sua influência dentro da empresa. Para Homburg et al. (1999) o papel do DM é facilitado quando o presidente ou o diretor-geral da empresa possui alguma formação em marketing, uma vez que seu estudo demonstrou que o conhecimento que o CEO tem sobre marketing influencia na reputação do DM dentro da organização. Dessa forma, sugere-se a seguinte hipótese:

$\mathrm{H}_{5}$ : $\mathrm{O}$ conhecimento de marketing do Reitor/Mantenedor das ICES está positivamente relacionado à reputação do Departamento de Marketing da instituição.

\section{RESPONSABILIDADES DO DEPARTAMENTO DE MARKETING}

As responsabilidades do DM de uma instituição de ensino superior, geralmente, são voltadas apenas para a promoção dos processos seletivos, propaganda e eventos, ou seja, debruçam-se somente sobre uma variável controlável do composto de marketing, a promoção (PUPO e BOTELHO, 2011). Todavia, a literatura de marketing prevê também a contemplação das outras três variáveis, ou seja, no apoio à concepção de novos cursos ou serviços, nas estratégias de preços e de local da oferta. Para tal, utiliza-se de pesquisas de mercado, análises dos ambientes de atuação da instituição, sejam eles macros (relativos aos ambientes externos à organização, como, os cenários econômico, político, legal, tecnológico, cultural e natural que a cercam) ou micros (concorrência, força de vendas, fornecedores e clientes). O alinhamento das quatro variáveis controláveis do composto de marketing permite à organização entregar maior valor 
para os seus clientes e potenciais clientes. Para Kotler e Reibstein (2013), uma empresa não deve deixar o seu produto ou serviço ser desenvolvido por um grupo, os seus preços definidos pelo outro grupo, os locais da oferta ou canais de distribuição determinados por um terceiro e a divulgação e as promoções desenvolvidas por um quarto grupo. Dessa forma, a seguinte hipótese foi formulada:

$\mathrm{H}_{6}$ : Quanto maior for a responsabilidade do Departamento de Marketing, tanto maior será a reputação deste dentro da instituição.

\section{Método da pesquisa e coleta DE DADos}

Para responder aos objetivos desse trabalho foi realizado, primeiramente, um estudo de natureza exploratória. Realizou-se a análise de fontes documentais ou bibliográficas, seguindo as definições de Appolinário (2009) que no Dicionário de Metodologia Científica as tratam como sinônimos.

Segundo Creswell (2007), a pesquisa exploratória proporciona melhor familiaridade com o tema e visa tornar o problema mais explícito, colaborando assim para a construção das hipóteses. Assim sendo, analisou-se documentos obtidos em fontes reguladas e gabaritadas no assunto, disponíveis no Ministério da Educação (MEC), no Instituto Nacional de Estudos e Pesquisas Educacionais Anísio Teixeira (INEP), na Associação Brasileira das Universidades Comunitárias (ABRUC), na Associação Nacional da Educação Católica (ANEC), no Sindicato das Mantenedoras de Ensino Superior (Semesp), em anuários de educação superior como o Guia do Estudante, em revistas de educação superior e de gestão, jornais, artigos acadêmicos, relatórios de consultorias educacionais, sites de universidades, portais de educação, redes sociais de empresas, pesquisas públicas, entre outros, cujo conteúdo seja pertinente a este estudo.

Para responder às questões de pesquisa e também aos objetivos gerais e específicos deste estudo, realizou-se uma pesquisa do tipo quantitativo-descritivos que utilizou o método survey, via questionário estruturado.

A pesquisa quantitativa é um meio para testar teorias objetivas examinando a relação entre as variáveis. O método survey, também traduzido por muitos autores como pesquisa de levantamento, proporciona uma descrição quantitativa de tendências, atitudes ou de opiniões de uma população, estudando uma amostra dessa população, utilizando questionários ou entrevistas estruturadas para 
a coleta de dados, com a intenção de generalizar a partir de uma amostra para uma população (CRESWELL, 2007).

A pesquisa foi apresentada e validada com dois especialistas do mercado educacional na posição de gestores de marketing de distintas ICES e também por uma banca de três pesquisadores: dois do programa de pós-graduação em Administração da PUC-SP e uma do programa de pós-graduação da USP.

A coleta dos dados foi por meio de questionário eletrônico, estruturado com perguntas fechadas com escalas de Likert e tipo Likert. A elaboração do questionário usou de constructos das Teorias em Marketing com o objetivo de obter dados que possibilitem o entendimento sobre a reputação do DM das Instituições Comunitárias de Ensino Superior e a sua relação com o grau de orientação para o mercado delas. De acordo com o Relatório de Gestão da ABRUC, há no Brasil 1.106 Instituições Comunitárias de Ensino Superior (ICES). Entretanto, no site dessa associação constam apenas 49 instituições listadas, com telefone e e-mail das suas respectivas Assessorias de Comunicação e Marketing. Boa parte dessas ICES são conhecidas e renomadas no mercado educacional, por exemplo, as PUCs (Pontifícia Universidade Católica), a Universidade Presbiteriana Mackenzie, a Universidade Metodista, o Centro Universitário São Camilo, bem como, as Universidades Católicas de Brasília e a de Salvador. Em função disso, a amostra foi do tipo não probabilístico por acessibilidade e conveniência dos autores. Também, foi considerado que as instituições que constam dessa lista possuem diferentes portes e organizações acadêmicas e são de diferentes regiões do país. Outras cinco instituições comunitárias, não listadas no site da ABRUC, também foram incluídas na amostra. O questionário foi encaminhado para o e-mail de 54 ICES, todavia, nove e-mails retornaram por endereço inválido. Buscaram-se, nas páginas de internet e nas redes sociais destas ICES, os contatos atualizados, tendo obtido retorno de seis. Logo, restaram 51 instituições. Das três instituições que não retornaram, pôde-se verificar que uma delas havia encerrado as atividades em 2013. Obteve-se o retorno de 21 instituições, o equivalente a uma taxa de respostas de $41 \%$.

\section{ANÁLISE DESCRITIVA DOS RESULTADOS}

O questionário foi integralmente preenchido pelos respondentes, logo, não houve dados faltantes. A taxa de resposta foi de $41 \%$, o equivalente a 21 instituições. Todas são instituições tradicionais 
com média de idade de 55 anos. Todos os respondentes afirmaram que a ICES possui um Departamento de Marketing (ou equivalente). As ICES que participaram da pesquisa são dos estados de São Paulo, Minas Gerais, Santa Catarina e Rio Grande do Sul, conforme demonstra na tabela 1.

Tabela 1 - Participação da ICES por Estado.

\begin{tabular}{|l|c|c|}
\hline \multicolumn{1}{|c}{ Estado } & \multicolumn{1}{c|}{ qtd } & \% \\
\hline São Paulo & 9 & $43 \%$ \\
\hline Minas Gerais & 4 & $19 \%$ \\
\hline Rio Grande do Sul & 6 & $29 \%$ \\
\hline Santa Catarina & 2 & $10 \%$ \\
\hline & $\mathbf{2 1}$ & $\mathbf{1 0 0} \%$ \\
\hline
\end{tabular}

Elaborado pelos autores

Os estados constantes na tabela 1 são representativos no setor da educação superior brasileira, pois estão situados em regiões que concentram o maior número de matrículas do país. A região Sudeste, principalmente o estado de São Paulo, é maior tanto em número de matrículas quanto em número de IES.

Observa-se no gráfico 1, as Universidades representam 71\% dos respondentes e os Centros Universitários, $29 \%$.

Gráfico 1 - Organização Acadêmica das ICES

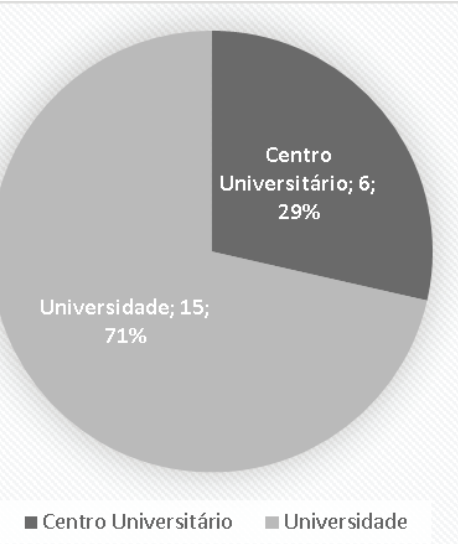

Elaborado pelos autores 
Em relação ao porte das ICES respondentes, 57\% são de grande porte e $43 \%$ de médio porte, vide gráfico 2 . Portanto, são instituições mais complexas para gerenciar, uma vez que possuem mais alunos, mais professores e mais funcionários, consequentemente, mais processos e maior custo operacional. Dessa forma, os departamentos de marketing dessas ICES tendem a ter a necessidade de captar uma quantidade grande de novos alunos, bem como a se preocupar com o volume de evasão e taxas de retenção. Logo, entende-se que o conhecimento aprofundado desses indicadores seja importante para que o planejamento de marketing da instituição seja mais eficaz.

Gráfico 2 - Porte das ICES

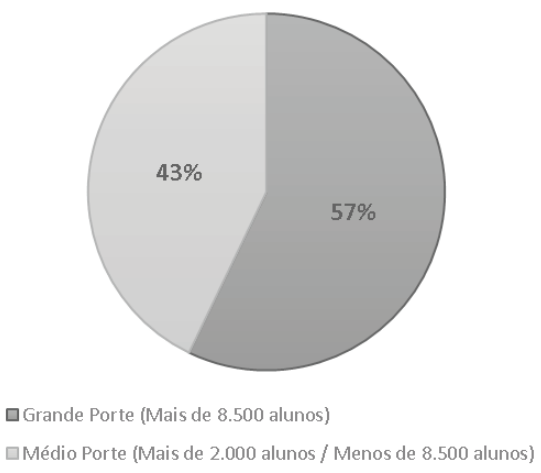

Elaborado pelos autores

Verifica-se também que $90 \%$ das ICES possuem a sua área de marketing diretamente ligada ao Reitor(a) ou à Mantenedora (vide tabela 2). Desses $71 \%$ são juntos à área de comunicação, ou seja, são denominados Departamento de Comunicação e Marketing. Os outros 19\% são denominados Departamento de Marketing. Isso nos mostra que poucas ICES compreendem o marketing de forma distinta à comunicação. O dado corrobora as teorias de Kotler (1995), Cobra e Braga (2004), Singh (2009) e Pupo e Botelho (2011) que afirmam serem raras as IES cujo marketing colabora com o plano de gestão da instituição. Em relação à posição hierárquica Gök et al. (2015) afirma que esta é um sinal de reputação para os stakeholders. Ou seja, 
os setores que estão mais bem posicionados na estrutura organizacional possuem melhor percepção entre aqueles que se relacionam com a instituição.

Tabela 2 - Posição Hierárquica do Departamento de Marketing das ICES.

\begin{tabular}{|l|c|c|}
\hline Posição Hierárquica do Departamento de Marketing & Qtd. & $\%$ \\
\hline $\begin{array}{l}\text { Temos um departamento de comunicação ou comunicação e marketing, } \\
\text { que NÃO se reporta diretamente ao Reitor(a) ou à Mantenedor(a). }\end{array}$ & 1 & $5 \%$ \\
\hline $\begin{array}{l}\text { Temos um departamento de comunicação ou comunicação e marketing, } \\
\text { que se reporta diretamente ao Reitor(a) ou à Mantenedor(a). }\end{array}$ & 15 & $71 \%$ \\
\hline $\begin{array}{l}\text { Temos um departamento de marketing separado que NÃO se reporta ao } \\
\text { Reitor(a) ou à Mantenedor(a). }\end{array}$ & 1 & $5 \%$ \\
\hline $\begin{array}{l}\text { Temos um departamento de marketing separado que se reporta ao } \\
\text { Reitor(a) ou à Mantenedor(a). }\end{array}$ & 4 & $19 \%$ \\
\hline Não temos um Departamento de Marketing Intitulado & 0 & $0 \%$ \\
\hline Total Geral & $\mathbf{2 1}$ & $\mathbf{1 0 0 \%}$ \\
\hline
\end{tabular}

Elaborado pelos autores

Os resultados apresentados na tabela 3 mostram que os Departamentos de Marketing das ICES estão, em sua maioria, organizados em Coordenadoria, 57\%, seguido por Gerência, 33\%. Apenas uma instituição possui uma Diretoria de Marketing. Nota-se também que somente uma instituição possui como responsável pela área de marketing um(a) Analista Sênior. A média de colaboradores desses departamentos é de 13 pessoas.

\section{Tabela 3 - Cargo do responsável pelo Departamento de Marketing}

\begin{tabular}{|c|c|c|}
\hline Cargo do Responsável pelo Departamento de Marketing & Qtd. & $\%$ \\
\hline Analista Sênior de Marketing (ou equivalente) & 1 & $5 \%$ \\
\hline Coordenador de Marketing (ou equivalente) & 12 & $57 \%$ \\
\hline Diretor de Marketing (ou equivalente) & 1 & $5 \%$ \\
\hline Gerente de Marketing (ou equivalente) & 7 & $33 \%$ \\
\hline Total Geral & 21 & $100 \%$ \\
\hline
\end{tabular}

Elaborado pelos autores

No que se refere à formação dos responsáveis pelo Departamento de Marketing, 57\% deles possuem graduação em Comunicação, 
sendo que 38\% são graduados e pós-graduados em Comunicação. Os graduados e pós-graduados em Administração representam 24\%. Os graduados em Comunicação e com pós-graduação em Administração somam $14 \%$, vide tabela 4 . A grande maioria desses profissionais possui mais de 5 anos de experiência, $90 \%$.

\section{Tabela 4 - Formação do Responsável pelo Departamento de Marketing}

\begin{tabular}{|l|r|}
\hline Formação do Responsável do Departamento de Marketing & \multicolumn{1}{c|}{$\%$} \\
\hline Graduado e Pós-graduado em Comunicação & $38 \%$ \\
\hline Graduado e Pós-graduado em Administração & $24 \%$ \\
\hline Graduado em Comunicação e Pós-graduado em Administração & $14 \%$ \\
\hline Graduado em Comunicação & $5 \%$ \\
\hline $\begin{array}{l}\text { Graduado em Processamento de Dados e Pós-Graduado em } \\
\text { Administração em Marketing }\end{array}$ & $5 \%$ \\
\hline Humanas - Geografia & $5 \%$ \\
\hline Marketing & $5 \%$ \\
\hline Mestrado em Educação & Total Geral \\
\hline
\end{tabular}

Elaborado pelos autores

Os resultados demonstrados nas tabelas 2 e 4 permitem-nos concluir, preliminarmente, que a área de marketing dentro da maioria das ICES é organizada mais pelos princípios da Comunicação do que pelos da Administração. A implicância disso na gestão é que os profissionais da comunicação não são formados para lidar com finanças, pois essa é uma disciplina da administração. Considerando os estudos de Homburg et al. (2015), o DM tem perdido influência dentro da organização justamente por não ser capaz de demonstrar os resultados financeiros de seus programas. 
Tabela 5 - Relação Cargo e Formação do Responsável pelo DM

\begin{tabular}{|l|r|}
\hline Diretor de Marketing (ou equivalente) & \\
\hline Graduado e Pós-graduado em Comunicação & 1 \\
\hline Gerente de Marketing (ou equivalente) & \\
\hline Graduado e Pós-graduado em Administração & 4 \\
\hline Graduado e Pós-graduado em Comunicação & 2 \\
\hline Graduado em Comunicação e Pós-graduado em Administração & 1 \\
\hline Coordenador de Marketing (ou equivalente) & \\
\hline Mestrado em Educação & 1 \\
\hline Graduado e Pós-graduado em Administração & 1 \\
\hline Graduado e Pós-graduado em Comunicação & 4 \\
\hline Graduado em Comunicação & 1 \\
\hline Graduado em Comunicação e Pós-graduado em Administração & 2 \\
\hline Graduado em Processamento de Dados e Pós-Graduado em Administração em Marketing & 1 \\
\hline Graduado em Geografia & 1 \\
\hline Graduado em Marketing & 1 \\
\hline Analista Sênior de Marketing (ou equivalente) & \\
\hline Graduado e Pós-graduado em Comunicação & 1 \\
\hline
\end{tabular}

Observa-se na tabela 5 que nas ICES pesquisadas não há qualquer relação entre o grau de formação do responsável pelo DM e o cargo que ele ocupa. Percebe-se que em muitas dessas instituições a estrutura organizacional não leva em consideração que o gestor desse departamento seja especializado em gestão ou marketing, como recomenda Andrade (2009). Profissionais sem formação ou especialização nessas áreas comprometem a habilidade em demonstrar como o setor contribui para os resultados da organização. Isso impacta na redução de orçamento e também de prestígio do DM, conforme apontaram Kumar e Shah (2009); Tavassoli et al. (2014) e Webster et al. (2005).

\section{ANÁlise ESTATíSTICA dos RESUltados}

Para rodar os testes estatísticos, foi utilizado o software SPSS. Por meio da estatística descritiva, verificou-se que todas as questões possuem o desvio-padrão positivo, indicando a normalidade do conjunto de itens. Para determinar o grau de confiabilidade utilizou-se o coeficiente alfa de Cronbach seguindo as classificações de Freitas e Rodrigues (2005). Assim, verificou-se que o valor de alfa $(\alpha=0,920)$ indica a alta confiabilidade do instrumento, permitindo maior ro- 
bustez à pesquisa realizada. Constatou-se também a consistência interna de cada item, sendo que as variáveis Responsabilidades do DM $(, 832)$ e Prestação de contas do DM $(, 800)$ foram consideradas altas. As variáveis Resposta ao cliente $(, 720)$, Disseminação da Informação $(, 669)$ e Reputação do DM $(, 632)$ tiveram um alfa de consistência moderado. As variáveis Conexão com clientes ( ,548) e Geração da Informação $(, 517)$ tiveram consistências baixas. A variável Integração do DM ( 223), que visa identificar o grau de integração do Departamento de Marketing das ICES com outros departamentos, teve uma consistência interna considerada muito baixa, como se pode verificar na tabela 6. De modo geral, pode-se afirmar que o conjunto de itens das variáveis apresenta bons índices de confiabilidade.

\section{Tabela 6 - Alfa de Cronbach}

\begin{tabular}{|l|l|l|}
\hline Variáveis & Valor de Alfa & Confiabilidade \\
\hline Responsabilidades do DM &, 832 & Alta \\
\hline Prestação de contas do DM &, 800 & Alta \\
\hline Resposta ao cliente &, 720 & Moderada \\
\hline Disseminação da Informação &, 669 & Moderada \\
\hline Reputação do DM &, 632 & Moderada \\
\hline Conexão com clientes &, 548 & Baixa \\
\hline Geração da Informação &, 517 & Baixa \\
\hline Integração do DM &, 223 & Muito baixa \\
\hline
\end{tabular}

Elaborado pelos autores

\section{ANÁliSE FATORIAL EXPLORATóRIA}

Para determinar o número ótimo de fatores que podem ser extraídos na análise fatorial exploratória, utilizou-se o critério da porcentagem da variância. Foram considerados como satisfatório os itens com coeficiente igual ou acima de 0,50. Ou seja, itens que tivessem um poder de explicação maior ou igual a 50\%. Pode-se observar que cinco fatores (componentes) somados são capazes de 
explicar $68,9 \%$ (vide Tabela 7). O componente 1 é o que tem o maior poder de explicação, 30\%. É mais que o dobro do componente 2, $12 \%$. Os componentes 3 e 4 possuem 9,7\% e 9,1\%, respectivamente. O componente 5 responde por 7,6\%.

Tabela 7-Autovalores e percentual de Variância Explicada pelos Fatores

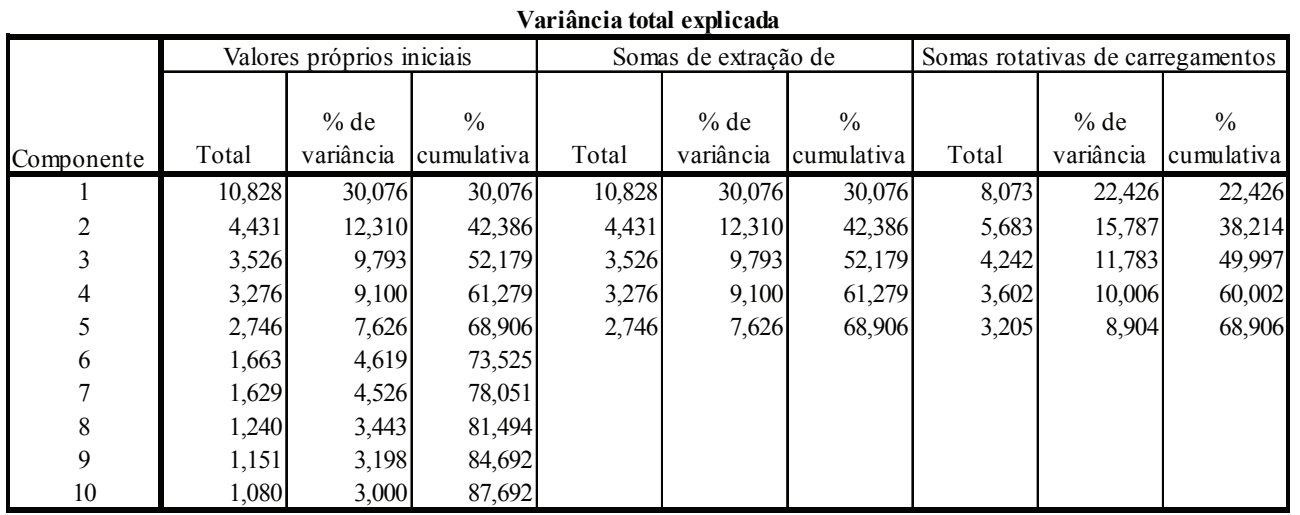

Método de Extração: Análise de Componente Principal.

Elaborado pelos autores

Por meio da matriz de componente de rotação, identificou-se que a maioria dos itens do componente 1 se refere aos aspectos da administração do marketing. Já no componente 2 referem-se ao envolvimento do Departamento de Marketing com outros departamentos da instituição. No componente 3 , todos os itens pertencem à variável "Orientação para o Mercado" e se referem à velocidade que a instituição age em certas situações. No componente 4, predomina a falta de atenção do DM com os resultados financeiros da instituição e o alto grau de dependência das políticas internas. Enquanto que no componente 5 predomina a variável resposta ao mercado. Verificou-se que apenas dois itens apresentaram variância percentual abaixo de $50 \%$. Em um deles, averiguou-se que o DM possui problemas na coordenação das atividades com outros departamentos, e outro item avalia os esforços dos departamentos das IES para programar alguma mudança desejada pelos alunos. 


\section{ANÁlise DE CORRELAÇÃo}

Para avaliar a correlação entre as variáveis, utilizou-se do coeficiente de Pearson. Verificou-se um total de 140 correlações com significância no nível 0,01 (2 extremidades), sendo 12 delas consideradas de grau forte, ou seja, são questões com alto poder de explicação entre elas. As correlações de grau moderado equivalem a $57 \%$ do total.

\section{ANÁliSE dA REGRESSÃo E VALIDAÇÃo DAS HIPóTESES}

$\mathrm{Na}$ análise de regressão linear múltipla, pode-se verificar um $\mathrm{R}^{2}$ $=0,824$, ou seja, as variáveis independentes conseguem explicar em média $82,4 \%$ da variação da variável dependente e o p-valor é menor 0,05 (vide Tabela 2). Dessa forma, pode-se afirmar que o modelo é significante e tem uma capacidade muito boa de explicação e que pelo menos uma das variáveis independentes tem influência sobre a variável dependente.

Tabela 8-Resumo do Modelo Proposto 1

\begin{tabular}{|c|c|c|c|c|c|c|c|c|c|}
\hline \multicolumn{10}{|c|}{ Resumo do modelo $^{\mathrm{b}}$} \\
\hline \multirow[b]{2}{*}{ Modelo } & \multirow[b]{2}{*}{$\mathrm{R}$} & \multirow[b]{2}{*}{$\begin{array}{c}\mathrm{R} \\
\text { quadrado }\end{array}$} & \multirow[b]{2}{*}{$\begin{array}{c}\mathrm{R} \\
\text { quadrado } \\
\text { ajustado }\end{array}$} & & \multicolumn{5}{|c|}{ Estatísticas de mudança } \\
\hline & & & & $\begin{array}{c}\text { Erro padrão da } \\
\text { estimativa }\end{array}$ & $\begin{array}{c}\text { Alteração } \\
\text { de R } \\
\text { quadrado }\end{array}$ & $\begin{array}{c}\text { Alteração } \\
\text { F }\end{array}$ & dfl & $\mathrm{df} 2$ & $\begin{array}{c}\text { Sig. } \\
\text { Alteração } \\
\text { F }\end{array}$ \\
\hline 1 &, $908^{\mathrm{a}}$ &, 824 &, 766 & ,72499 & ,824 & 14,073 & 5 & 15 & 000 \\
\hline
\end{tabular}

a. Preditores: (Constante), Conhecimento CEO, Integração do DM, Prestação de Contas do DM, Conexão do DM, Responsabilidades do DM b. Variável Dependente: Reputação do DM

Elaborado pelos autores

Por meio desta análise, verificou-se a significância estatística dos parâmetros de cada variável independente e a possibilidade de suporte às hipóteses apresentadas.

Como se pode observar na Tabela 9, os resultados demonstraram que as variáveis Conhecimento do CEO (Reitor/Mantenedor) e Responsabilidades do DM exercem uma influência forte e significante sobre a reputação do DM dentro das ICES $(\mathrm{p}<.01)$. Assim, pode-se afirmar que as hipóteses $\mathrm{H}_{5}$ e $\mathrm{H}_{6}$ foram corroboradas pelo modelo estatístico. Os resultados também revelaram que a capacidade do DM de se conectar com seus clientes e potenciais clientes não está significativamente relacionada à reputação deste dentro das ICES. 
O mesmo ocorre com as variáveis Integração do DM e Prestação de Contas do DM. Assim, $\mathrm{H}_{2}, \mathrm{H}_{3}$ e $\mathrm{H}_{4}$ não foram suportadas.

Tabela 9- Significância dos Parâmetros de Regressão Múltipla

\begin{tabular}{|c|c|c|c|c|c|c|c|c|}
\hline \multicolumn{9}{|c|}{ Coeficientes $^{a}$} \\
\hline \multirow[b]{2}{*}{ Modelo } & & \multicolumn{2}{|c|}{$\begin{array}{c}\text { Coeficientes não } \\
\text { padronizados }\end{array}$} & $\begin{array}{l}\text { Coeficientes } \\
\text { padronizados }\end{array}$ & \multirow[b]{2}{*}{$t$} & \multirow[b]{2}{*}{ Sig. } & \multicolumn{2}{|c|}{$\begin{array}{c}95,0 \% \text { Intervalo de } \\
\text { Confiança para B }\end{array}$} \\
\hline & & B & $\begin{array}{c}\text { Erro } \\
\text { Padrão }\end{array}$ & Beta & & & $\begin{array}{l}\text { Limite } \\
\text { inferior }\end{array}$ & $\begin{array}{l}\text { Limite } \\
\text { superior }\end{array}$ \\
\hline 1 & (Constante) &,- 459 & 1,040 & &,- 441 & ,665 & $-2,676$ & 1,758 \\
\hline & Responsabilidades_do_DM & ,728 &, 260 & ,658 & 2,802 & ,013 & 174 & 1,282 \\
\hline & Prestação de Contas do DM &,- 408 & ,371 &,- 245 & $-1,098$ & ,289 & $-1,199$ & ,383 \\
\hline & Conexão do DM &,- 098 & ,170 &,- 079 &,- 575 &, 574 &,- 461 & ,265 \\
\hline & Integração do DM & ,279 & ,198 & ,183 & 1,412 &, 178 &,- 142 & ,700 \\
\hline & Conhecimento CEO & ,602 & 107 & ,668 & 5,622 & 000 & ,374 & ,831 \\
\hline
\end{tabular}

Elaborado pelos autores

Rodou-se novamente uma nova regressão linear múltipla utilizando apenas as duas variáveis significantes para verificar a consistência dessas sobre o modelo. Verificou-se o valor de $\mathrm{R}^{2}=0,791$, que pode ser considerado muito bom. Isso nos mostra que as variáveis independentes, Conhecimento do CEO e Responsabilidades do DM, explicam, em média, 79,1\% da variância da Reputação do DM (variável dependente). O p-valor continuou significativo $(\mathrm{p}<.01)$, conforme pode-se observar na Tabela 10.

Tabela 10-Resumo do Modelo Proposto 2

\begin{tabular}{|c|c|c|c|c|c|c|c|c|c|}
\hline \multicolumn{10}{|c|}{ Res umo do modelo $^{\mathrm{b}}$} \\
\hline \multirow[b]{2}{*}{ Modelo } & \multirow[b]{2}{*}{$\mathrm{R}$} & \multirow[b]{2}{*}{$\begin{array}{c}\mathrm{R} \\
\text { quadrado }\end{array}$} & \multirow[b]{2}{*}{$\begin{array}{c}\mathrm{R} \\
\text { quadrado } \\
\text { ajustado }\end{array}$} & \multirow[b]{2}{*}{$\begin{array}{c}\text { Erro } \\
\text { padrão da } \\
\text { estimativa }\end{array}$} & \multicolumn{5}{|c|}{ Estatísticas de mudança } \\
\hline & & & & & $\begin{array}{c}\text { Alteração } \\
\text { de R } \\
\text { quadrado }\end{array}$ & $\begin{array}{c}\text { Alteração } \\
\text { F }\end{array}$ & df1 & $\mathrm{df} 2$ & $\begin{array}{c}\text { Sig. } \\
\text { Alteração } \\
\text { F }\end{array}$ \\
\hline 1 &, $889^{\mathrm{a}}$ & ,791 & ,768 &, 72220 & ,791 & 34,011 & 2 & 18 & 000 \\
\hline
\end{tabular}

a. Preditores: (Constante), Conhecimento CEO, Responsabilidades_do_DM

b. Variável Dependente: Reputação do DM

Elaborado pelos autores

\section{ORIENTAÇÃo PARA O MERCAdo}

O modelo de mensuração e análise do grau de orientação para o mercado das ICES pesquisadas baseou-se nos trabalhos de Sampaio 
(2000) e Franco (2014) que adaptaram e aplicaram a escala MARKOR, originalmente de Kohli e Jaworski (1993), no contexto brasileiro. No tocante à geração da informação, verificou-se na Tabela 11 que uma mediana (Q30) ficou abaixo do ponto médio da escala e uma mediana (Q33) se situa no ponto máximo da escala. Em dois itens dessa variável (Q34 e Q35) a mediana foi igual 4. A média total da variável geração da informação é de 3,31.

Tabela 11-Média, Mediana e Desvio-padrão dos itens de Geração de Informação

\begin{tabular}{|c|c|c|c|c|c|}
\hline \multicolumn{2}{|r|}{ Geração da Informação } & Média & Mediana & $\begin{array}{l}\text { Des vio } \\
\text { padrão }\end{array}$ & $\begin{array}{c}\text { Média } \\
\text { total }\end{array}$ \\
\hline$Q 30$ & Reune com Alunos para identificar necess futuras & 2,43 & 2,0 & 1,43 & \multirow{6}{*}{3,31} \\
\hline$Q 31$ & A própria IES faz muitas pesquisas de mercado & 3,14 & 3,0 & 1,42 & \\
\hline$Q 32$ & Somos lentos para detectar mudanças preferencias dos alunos & 2,90 & 3,0 & 0,89 & \\
\hline$Q 33$ & Medimos a qualidade dos cursos e serviços anualmente & 4,19 & 5,0 & 1,21 & \\
\hline$Q 34$ & Somos lentos para detectar mudanças ramo de atividade & 3,71 & 4,0 & 0,90 & \\
\hline$Q 35$ & Revisamos os efeitos da mudanças ambiente de negócios nos alunos & 3,48 & 4,0 & 1,21 & \\
\hline
\end{tabular}

Nivel de confiança de $95 \%$

Elaborado pelos autores

Em relação à disseminação da informação nota-se, na Tabela 12, que não houve qualquer item com mediana abaixo do ponto médio da escala. Todavia, também não se verificou qualquer mediana no ponto máximo. Os itens Q36, Q37, Q39 e Q40 apresentaram mediana no ponto médio da escala. O item Q38 teve a mediana acima do ponto médio. A média geral dessa variável foi de 3,24.

Tabela 12- Média, Mediana e Desvio-padrão dos itens de Disseminação da Informação

\begin{tabular}{|c|c|c|c|c|c|}
\hline \multicolumn{2}{|r|}{ Dis s eminação da Informação } & \multirow{2}{*}{$\begin{array}{c}\text { Média } \\
3,10\end{array}$} & \multirow{2}{*}{$\begin{array}{c}\text { Mediana } \\
3\end{array}$} & \multirow{2}{*}{$\begin{array}{c}\begin{array}{c}\text { Des vio } \\
\text { padrão }\end{array} \\
1,26 \\
\end{array}$} & $\begin{array}{l}\text { Média } \\
\text { Total }\end{array}$ \\
\hline$Q 36$ & Reuniao entre dpto para discutir tendencias de mercado & & & & \multirow{5}{*}{3,24} \\
\hline$Q 37$ & O DM investe tempo discutindo outros dpto necessidades alunos & 2,86 & 3 & 1,39 & \\
\hline$Q 38$ & Agilidade entre os dptos & 3,90 & 4 & 1,18 & \\
\hline$Q 39$ & Compartilha dados da satisfação dos alunos em todos niveis & 3,48 & 3 & 0,93 & \\
\hline$Q 40$ & Somos lentos para alertar outros dptos & 2,86 & 3 & 1,11 & \\
\hline
\end{tabular}

Nivel de confiança de $95 \%$

Elaborado pelos autores 
A variável que mede a resposta ao mercado apresentou uma mediana (Q46) abaixo do ponto médio e nenhuma no ponto máximo da escala. A maioria dos itens (Q41, Q42, Q43, Q45 e Q47) apresentou mediana no ponto médio da escala. O item Q46 teve mediana acima do ponto médio. A média total para essa variável foi de 2,81, como se pode verificar na Tabela 13.

Tabela 13- Média, Mediana e Desvio-padrão dos itens de Resposta ao Mercado

\begin{tabular}{|l|l|c|c|c|}
\hline \multicolumn{1}{|c|}{ Res pos ta ao mercado } & Média & Mediana & $\begin{array}{c}\text { Des vio } \\
\text { padrão }\end{array}$ & $\begin{array}{c}\text { Média } \\
\text { Total }\end{array}$ \\
\hline$Q 41$ & Demoramos para responder às mudanças de preço & 2,57 & 3 & 0,93 \\
\hline$Q 42$ & Ignoramos necessidades mudanças nos cursos e serviço & 3,10 & 3 & 1,22 \\
\hline$Q 43$ & Varios dptos reunem-se para planejar respostas às mudanç de mercado & 2,71 & 3 & 1,10 \\
\hline$Q 44$ & Atividades de diferentes áreas são bem coordenadas & 3,33 & 4 & 0,97 \\
\hline$Q 45$ & Não somos capazes de implementar plano marketing em tempo hábil & 3,19 & 3 & 1,25 \\
\hline$Q 46$ & Os dptos se es forçam para implementar mudanças desejadas pelos alunos & 2,48 & 2 & 1,03 \\
\hline Q47 & Os cursos dependem mais de politicas internas do que do mercado & 2,29 & 3 & 1,27 \\
\hline
\end{tabular}

Nivel de confiança de $95 \%$

Elaborado pelos autores

Para se chegar ao valor que define o nível de orientação para o mercado, foi tirada a média aritmética entre as médias totais das três variáveis (Geração da Informação, Disseminação da Informação e Resposta ao Mercado). A estatística descritiva, vide Tabela 14, demonstra que as ICES estão discretamente acima do ponto médio da escala $(3,15)$. Dessa forma, é possível afirmar que há suporte empírico para $\mathrm{H}_{1(\mathrm{a})}$.

Tabela 14-Média, Desvio Padrão e Variância de Orientação para o Mercado

Es tatís tica des critva

\begin{tabular}{|l|l|l|c|c|}
\hline & $\mathrm{N}$ & Média & $\begin{array}{c}\text { Desvio } \\
\text { Padrão }\end{array}$ & Variância \\
\hline Orientação ao mercado & 21 & 3,1509 &, 46452 &, 216 \\
N válido (de lista) & 21 & & & \\
\hline
\end{tabular}

Elaborado pelos autores

A relação entre a reputação do DM e a orientação para o mercado das ICES 
Para verificar a relação existente entre a reputação do DM com o nível de orientação para o mercado das ICES, rodou-se um teste - T de uma amostra com intervalo de confiança de 95\% (vide Tabela 15). Esse teste revelou que há significância assintótica entre as variáveis $(\mathrm{p}<.01)$, o que indica forte suporte para $\mathrm{H}_{1(\mathrm{~b}) .}$ Ou seja, a reputação do DM exerce forte influência positiva no nível de orientação para o mercado das ICES.

Tabela 15- Teste - T entre Reputação do DM e Orientação para o Mercado

Teste de uma amostra

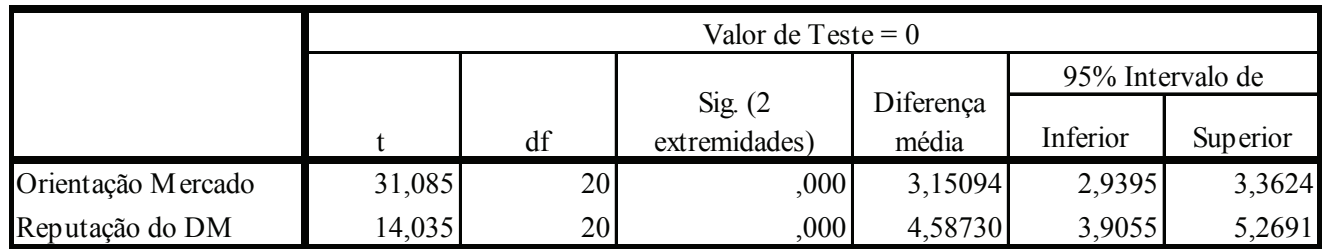

Elaborado pelos autores

\section{DiscuSSÃo doS RESULTADOS}

A diretriz mais eficaz desta investigação para fundamentar a aplicabilidade do questionário de pesquisa foi a abordagem de Gök et al. (2015), que analisou a reputação do DM nas organizações e sua influência sobre o desempenho organizacional. Os autores salientam que capacidades do DM, como prestar contas à gestão, conectar-se com os clientes e cooperar com outros departamentos, influenciam positivamente na reputação do departamento. Já a compilação dos trabalhos de Pupo e Botelho (2011) e Kotler e Fox (1995) permitiu indicar que, de modo geral, as Responsabilidades do DM devem ir além de divulgar processos seletivos, e que o alinhamento do composto de marketing (4Ps) permite entregar maior valor para os clientes. Por conseguinte, melhores resultados para instituição. Por fim, o trabalho de Homburg et al. (1999), que analisou a influência do marketing dentro da organização, demonstrou que o conhecimento do CEO sobre o assunto é um fator determinante.

De acordo com Andrade (2009), os coordenadores de marketing têm atuação mais voltada para a estruturação da estratégia de projeto, pesquisa do macroambiente, análise do mercado, desenvolvimen- 
to de propaganda e promoções e implantação de ações de relações públicas e assessoria de imprensa. Já os gerentes e os diretores de marketing, além de atuar no nível da coordenação e da execução das atividades de comunicação, comercialização e marketing, são também aptos a assessorar a diretoria e os setores da empresa, gerenciar recursos humanos, administrar recursos financeiros e materiais, bem como, promover condições de segurança, saúde, meio ambiente e qualidade. Os resultados aqui apresentados demonstram que a forma como estão organizados os Departamentos de Marketing explicam o fato do item Q25 da pesquisa (que avalia se o DM assessora a alta administração) não ter apresentado qualquer correlação com o item Q26 (que avalia se o responsável pelo DM tem assento garantido nas reuniões de gerência das ICES).

Verificou-se também que o grau de conhecimento do Reitor/ Mantenedor das ICES é o que mais interfere na reputação do DM. Essa constatação confirma a teoria de Homburg et al. (1999), de que DM tem mais influência nas organizações cujo CEO tem experiência ou formação em marketing. Nesta pesquisa, esse grau de conhecimento foi pontuado pelos gestores das áreas de marketing, com base em suas próprias experiências com a administração das ICES. Devido à inconsistência dos dados relacionados à formação acadêmica do Reitor/Mantenedor, não foi possível relacioná-la à nota atribuída.

Esta pesquisa também mostrou que a variável independente Responsabilidades do DM exerce influência positiva sobre a variável dependente Reputação do DM. Isso permitiu concluir que as ICES pesquisadas vêm desenvolvendo um trabalho de marketing mais robusto, com funções que vão além da simples operação de divulgar os processos seletivos e organizar eventos. Quatro dos cinco itens dessa variável apresentaram pelo menos uma correlação forte positiva com o modelo. O único que não teve foi justamente aquele que avalia se o DM cuida somente da divulgação dos processos seletivos. Tais resultados demonstram que o DM dessas instituições está investindo mais em pesquisas de satisfação com os alunos, em assessorar os coordenadores de cursos e em organizar um painel de métricas. São funções mais estratégicas do que operacionais. Isso indica que essas ICES apresentaram uma boa evolução frente 
aos resultados alcançados nos estudos de Pupo e Botelho (2011) e Kotler e Fox (1995).

Diferentemente dos resultados demonstrados no estudo de Gök et al. (2015), a variável independente Prestação de Contas não apresentou relação positiva direta com a Reputação do DM. Entretanto, percebe-se pelas análises de correlações que o DM dessas instituições tem se preocupado com a apresentação de previsão de ROI e estudos de viabilidade econômica e financeira nos seus planos estratégicos. Isso indica que alguns desses DM têm buscado conectar seus planos de marketing aos resultados financeiros das IES. O trabalho de Homburg et al. (2015) indica que, com frequência, tem se observado a falta de habilidade dos profissionais de marketing para a sua influência nos resultados da empresa. A capacidade desse profissional em demonstrar estudos financeiros coerentes e consistentes poderá, a médio prazo, melhorar a confiança do Reitor/ Mantenedor em relação ao setor.

A variável independente Conexão do DM com os alunos e potenciais alunos das IES também não apresentou relação positiva direta com a variável dependente Reputação do DM. Um dos itens desse constructo não mostrou correlação com qualquer outro. Trata-se do item que avalia a habilidade do DM para traduzir as necessidades dos alunos e potenciais alunos em especificações técnicas. Isso enfraqueceu o constructo, que nos demais itens apresentou correlações moderadas. Pode-se concluir que o DM está identificando, através das pesquisas de satisfação, as necessidades dos alunos. Todavia, ainda encontra dificuldades para traduzi-las de forma eficaz, fazendo-se necessária uma revisão tanto na metodologia de investigação quanto na interpretação dos resultados.

Nesta investigação também se verificou que o constructo Integração do DM com outros setores não influencia a reputação deste. O único item do constructo que apresentou correlação com outros itens foi o que averigua o fato de outros departamentos das IES compartilharem os dados com o DM. No geral, essa correlação é positiva. Destaca-se nesta análise que o item que avalia se o DM compartilha seus dados com outros setores apresenta poucas correlações com outros itens do modelo. Foram somente duas, e com grau fraco. Isso indica que o DM nessas ICES tende a colher mais informações 
do que a compartilhar. É importante para a instituição que todos os setores estratégicos saibam que exercem relações de marketing (YANAZE, 2011). Partilhar, estrategicamente, as informações colhidas pelo DM em toda a organização é fundamental para se ter um marketing mais efetivo. Além do mais, é uma forma de demonstrar aos demais setores o trabalho que está sendo desenvolvido pelo DM e também de criar uma relação de troca, diminuindo possíveis desconfianças e rivalidades interdepartamental. A pesquisa de Gök et al. (2015) aponta que a colaboração com outros departamentos da instituição é determinante para uma reputação positiva. Estevão, Mainardes e Raposo (2009) afirmam que a integração harmônica entre os setores da empresa beneficia a disseminação de toda a inteligência de mercado colhida pelo DM.

No geral, constatou-se que a reputação do DM nas ICES pesquisadas é mediana. Apesar de não ser alta, pôde-se concluir que o resultado é satisfatório, considerando os diversos trabalhos publicados que apontam o DM das IES como o setor que cuida apenas da publicidade e da promoção de seus processos seletivos.

No tocante à orientação para o mercado, verificou-se que as ICES pesquisadas apresentaram resultados medianos, ou seja, a geração e a disseminação da informação ficaram no ponto médio da escala. Estevão, Mainardes e Raposo (2009) apontam que a dificuldade de disseminar internamente as informações é um dos obstáculos à melhoria das organizações em relação a se orientar para o mercado. A variável que mede o grau de resposta ao mercado ficou abaixo do ponto médio. Os estudos de Kotler e Keller (2006) afirmam que orientar uma instituição pelo marketing poderá trazer benefícios como: 1) aumentar o nível de profissionalização da instituição; 2) tornar transparente a qualidade dos serviços prestados pela instituição; 3) obrigar a instituição a definir missão, metas e objetivos; 4) impelir a instituição a trabalhar com planejamento estratégico; posicionar a instituição no mercado; 5) selecionar mercados-alvo, distinguindo os melhores segmentos com potencial de mercado; 6) auxiliar na melhoria do produto ou serviço oferecido pela instituição, uma vez que ela se volta para o atendimento das necessidades dos clientes; 7) melhorar a satisfação dos diversos públicos da instituição.

Os resultados também demonstraram que a reputação do DM 
influencia positivamente no grau de orientação para o mercado. Logo, quanto melhor for a reputação do Departamento de Marketing dentro das ICES, tanto melhor será o seu grau de orientação para o mercado.

\section{CONSIDERAÇões FINAIS}

O objetivo geral deste artigo foi investigar a reputação do Departamento de Marketing nas Instituições Comunitárias de Ensino Superior. Procurou-se entender como essas ICES têm organizado e estruturado essa unidade para enfrentar os desafios impostos pelo atual ambiente de negócios, que vem sofrendo os impactos da crise política e econômica do país.

O primeiro objetivo específico foi entender o nível de integração do DM com a gestão acadêmica e administrativa das ICES. Os resultados da análise fatorial demonstraram que a interação interdepartamental foi um dos componentes que, no modelo proposto, apresentaram itens com poder de explicação igual ou acima de 50\%. Isso se deu, principalmente, em respeito à disseminação da informação. Ou seja, de modo geral, o DM dessas ICES faz muitas pesquisas e os resultados são compartilhados com outros departamentos. Isso favorece as instituições, pois todos passam a conhecer mais sobre o perfil dos estudantes, dos candidatos, da concorrência e do ambiente em que atuam podendo, assim, elaborar estratégias e processos mais eficazes. Fazer uma gestão de curso ou da instituição valendo-se das informações produzidas pelo marketing pode ajudar a administração a criar vantagens competitivas claras e verdadeiras. Em um cenário cada vez mais disputado, tais vantagens podem sustentar inclusive as IES que praticam preços de mensalidades mais elitizados. Toda a instituição (alunos, professores e funcionários) deverá adotar esses diferenciais em seus discursos frente ao público-alvo. O DM também deverá cuidar para que esses benefícios fiquem claros na publicidade e nas suas ações de marketing.

O segundo objetivo específico buscou avaliar o nível da reputação do DM nas referidas ICES. Percebeu-se que em algumas instituições o Departamento de Marketing tem assento garantido na reunião de gerentes. Também conseguem com facilidade recursos que garantem o bom andamento do trabalho, como pessoas, 
softwares, orçamento, além de assessorar a alta administração. Porém, notou-se que em muitas instituições o cargo do responsável é abaixo de gerente. Isso significa possuir menos prestígio na gestão, pois não estar em nível de igualdade impacta na credibilidade do departamento junto às demais gerências e enfraquece o trabalho desenvolvido pelo setor. No geral, pôde-se concluir que a reputação é mediana. Os resultados desta pesquisa demonstram que algumas dessas ICES já possuem um Departamento de Marketing mais consolidado e preparado para entender corretamente o ambiente de negócios e assessorar a Reitoria/Mantenedora. Pode-se dizer que tais instituições estão melhor preparadas para lidar com as questões que envolvem o mercado educacional e conseguem ter uma atuação mais estratégica. Outras estão evoluindo aos poucos, todavia, apresentaram-se indícios de que o DM não está atuando somente na divulgação dos processos seletivos, como apontam alguns estudos já mencionados neste trabalho, ele também tem cumprido uma função tática na gestão das ICES. Considerando o fato de que, por muito tempo, as instituições mais tradicionais não se sentiam ameaçadas por uma concorrência e, portanto, não tinham tanta preocupação com o marketing, acredita-se que os resultados foram satisfatórios.

O terceiro, e último, objetivo específico foi avaliar o grau de orientação para o mercado das ICES. A medição foi feita utilizando a escala MARKOR, adaptada para o segmento da educação superior. Tal escala considera três atributos de aferição: 1) as capacidades da instituição de gerar informação; 2) disseminar essa informação internamente e; 3 ) capacidade de dar respostas ao mercado. Os resultados obtidos mostram que as ICES atuam de forma mediana nos dois primeiros e abaixo da média no terceiro. O resultado é coerente com o encontrado no segundo objetivo, uma vez que esta pesquisa permitiu verificar que a reputação do Departamento de Marketing tem influência positiva sobre o grau de orientação para o mercado das ICES. Dessa forma, quanto melhor for a reputação do DM, tanto melhor será a capacidade da instituição de gerar e compartilhar informações e de dar respostas ao mercado em tempo hábil, tornando-se assim mais competitiva.

Os resultados demonstram que há um esforço por parte de algumas ICES em fortalecer o Departamento de Marketing dentro 
da instituição. No entanto, é preciso que o Reitor/Mantenedor tenha uma correta visão do que é marketing e dos benefícios que ele pode trazer para a gestão da instituição. Dessa forma, poderá organizar uma estrutura de marketing com condições de realizar um trabalho eficaz. Criar essas condições implicará investimento na capacitação dos profissionais do setor. Os gestores de marketing precisam ser competentes para conectar o plano de marketing aos resultados financeiros das IES, bem como, para traduzir melhor as necessidades dos alunos no plano estratégico, dadas as razões aqui já destacadas.

A maior limitação desta pesquisa está relacionada à amostra, visto que o relatório de gestão da ABRUC aponta a existência de 1.106 ICES, mas apenas 49 são listadas em sua página na internet, estando muitas delas com os contatos desatualizados.

Recomenda-se, como sugestão de estudos futuros, que este modelo investigativo seja replicado também nas IES privadas não comunitárias, a fim de verificar se há semelhanças e/ou diferenças em relação à reputação do Departamento de Marketing, bem como, se essas instituições atuam com maior ou menor grau de orientação para o mercado.

Por fim, almeja-se que este artigo possa contribuir com o meio acadêmico e estimular novas investigações acerca do tema no Brasil. Espera-se, ainda, que seja útil aos gestores de marketing das IES e seus respectivos reitores/mantenedores, na formatação e compreensão de um Departamento de Marketing mais forte e colaborativo.

\section{REFERÊNCIAS}

ABRUC. Relatório de Gestão, 2009-2013. Brasília, 2013. Disponível em: http://www.abruc.org.br/. Acessado em: 02/12/2013.

ACHROL, Ravi S.; KOTLER, Philip. Marketing in the Network Economy. Journal of Marketing, v. 63 (Special Issue, 1999), p. 146-163.

ANDERSON, Paul F. Marketing, strategic planning, and the theory of the firm. In: Journal of Marketing, 46, (2), 1982, 15-26, Chicago, III.

ANDRADE, Carlos Frederico de. Marketing: O que é? Quem faz? Quais as tendências? Curitiba: IBPEX, 2009.

ANTONI, V. L.; DAMACENA, C.; LEZANA, A. G. R. L. Um modelo preditivo de orientação para o mercado: um estudo no contexto do ensino superior brasileiro. In: Encontro Nacional da Associação dos Programas de Pós-Graduação e Pesquisa em Administração, 28, 2004, Curitiba. Anais. Curitiba: ANPAD, 2004. 
APPOLINÁRIO, F. Dicionário de metodologia científica: um guia para a produção do conhecimento científico. São Paulo, Atlas, 2009.

COBRA, Marcos. BRAGA, Ryon. Marketing educacional: ferramentas de gestão para instituições de ensino. São Paulo: Cobra: Hoper, 2004.

CRESWELL J. W. Projeto de pesquisa: métodos qualitativo, quantitativo e misto, 2. ed. Porto Alegre: Artmed, 2007.

DAY, G. Market Driven Strategy: Process for Creating Value. New York: Free Press, 1990.

DENG, Shengliang; DART, Jack. Measuring market orientation: a multi $\square$ factor, multi-item approach. Journal of marketing management, v. 10, n. 8, p. 725-742, 1994.

DESHPANDE, Rohit; FARLEY, John U.; WEBSTER JR, Frederick E. Corporate culture, customer orientation, and innovativeness in Japanese firms: a quadrad analysis. Journal of Marketing, p. 23-37, 1993.

ENSINO Superior 2015. Guia do Estudante. São Paulo: Ed. Abril, s.d.

ESTEVÃO, Cristina; MAINARDES, Emerson; RAPOSO, Mario. Orientação para o Mercado no Segmento Hoteleiro: o caso português. Turismo em análise, p. 446-468, 2009.

FENG, Hui, MORGAN, Neil A., REGO, Lopo L. Marketing Department Power and Firm Performance. Journal of Marketing, v. 79, p. 1-20, 2015.

FRANCO, Gilmar de Souza. Orientação para o Mercado em Instituições de Ensino Superior, 2014, 181 p. Tese de Doutorado. Universidade de Trás-os-Montes e Alto Douro.

GÖK, Osman; PEKER, Sinem; HACIOGLU, Gungor. The marketing department's reputation in the firm. European Management Journal, v. 33, p. 366-380, 2015.

GOMES, Giancarlo; SILVEIRA, Amelia; DE SOUZA, Maria José Barbosa. Plano de marketing: um olhar mais acurado sobre a adoção em instituições de ensino superior brasileiras. Revista Gestão Universitária na América Latina-GUAL, v. 6, n. 2, p. 185-209, 2013.

GRUCA, Thomas S.; REGO, Lopo L. Customer satisfaction, cash flow, and shareholder value. Journal of Marketing, v. 69, n. 3, p. 1-130, 2005.

HOMBURG, Christian et al. The loss of the marketing department's influence: is it really happening? And why worry? Journal of the Academy of Marketing Science, v. 43, n. 1, p. 1-13, 2015.

HOMBURG, Christian; WORKMAN JR, John P.; KROHMER, Harley. Marketing's influence within the firm. Journal of Marketing, p. 1-17, 1999.

HUBERMAN, B.A.; LOCH, C. H.; ÖNÇULER, A. Status as valued resource. Social Psychology Quarterly, 67 (1), p. 103-114. In: GÖK, Osman; PEKER, Sinem; HACIOGLU, Gungor. The marketing department's reputation in the firm. European Management Journal, v. 33, p. 366-380, 2015.

KAHN, K. B. Department status: An exploratory investigation of direct and indirect effects on product development performance. Journal of Product Innovation Management, 22 (6), p. 515-526. 
KAUR, Gurjeet; GUPTA, Mahesh C. A perusal of extant literature on market orientation-concern for its implementation. The Marketing Review, v. 10, n. 1, p. 87-105, 2010.

KOHLI, Ajay K.; JAWORSKI, Bernard J. Market orientation: the construct, research propositions, and managerial implications. Journal of Marketing, p. 1-18, 1990.

KOHLI, Ajay K.; JAWORSKI, Bernard J.; KUMAR, Ajith. MARKOR: a measure of market orientation. Journal of Marketing research, p. 467-477, 1993.

KOTLER, Philip e KELlER, Kevin L. Administração de Marketing. São Paulo: Pearson Prentice Hall, 2006.

KOTLER, Philip. FOX, K. F. A. Strategic Marketing for Educational Institutional. New York: Prentice-Hall, 1995.

KOTLER, Philip; ARMSTRONG, Gary. Princípios de Marketing. São Paulo: Pearson Education $-\mathrm{Br}, 2014$.

KOTLER, Philip; REIBSTEIN, David. Does your company really need a marketing department? Marketing News, p. 20-21, 2013.

KUMAR, V.; SHAH, D. Expanding the role of marketing: from customer equity to market capitalization. Journal of Marketing, 73, 119-136, 2009.

LANGE, Donald; LEE, Peggy M.; DAI, Ye. Organizational reputation: A review. Journal of Management, v. 37, n. 1, p. 153-184, 2011.

MENNA, H. L. Orientação para o mercado e performance: evidências em empresas gaúchas de varejo de confecções masculinas. In: Encontro Nacional da Associação dos Programas de Pós-Graduação e Pesquisa em Administração, 25., 2001, Campinas. Anais. Campinas: ANPAD, 2001.

MEYER JR., Vitor; MURPHY, J. Patrick. Dinossauros, gazelas e tigres: novas abordagens da administração universitária. Florianópolis: Insular, 2003.

NARVER, John C.; SLATER, Stanley F. The effect of a market orientation on business profitability. The Journal of marketing, p. 20-35, 1990.

NATH, Pravin; MAHAJAN, Vijay. Chief Marketing Officers: A Study of Their Presence in Firm's Top Management Teams. Journal of Marketing, v. 72, p. 65-81, 2008.

NUNES, G. T. et al. Emergência do Marketing nas Instituições de Ensino Superior: Um estudo exploratório. In: Análise, v. 19, n. 1, p. 173-198. Porto Alegre, jan/jun. 2008.

O'SULLIVAN, Don; ABELA, Andrew V. Marketing performance measurement ability and firm performance. Journal of Marketing, v. 71, n. 2, p. 79-93, 2007.

PERIN, M. G.; SAMPAIO, C. H. Orientação empresarial, porte empresarial e performance. Revista de Administração de Empresas, v. 44, n. 3, p. 76-88, 2004.

PFEIFER, J.; SALANCIK, G. The External Control of Companies: A Resource Dependence Perspective. 1978.

PUPO, Fabricio Palermo; BOTELHO, Delane. Conhecimento e uso de métricas de marketing. Revista pensamento contemporâneo em administração, v. 5, n. 1, p. 38-55, 2011. 
SAMPAIO, C. H. Relação entre Orientação para o Mercado e Performance Empresarial em Empresas de Varejo de Vestuário no Brasil. 2000. p. 234.Tese de Doutorado. Universidade Federal do Rio Grande do Sul.

SAMPAIO, C. H.; PERIN, M. G., HENRIQSON, E. Orientação para o mercado, orientação para aprendizagem e porte empresarial como antecedentes das dimensões da performance. In: Encontro Nacional da Associação dos Programas de Pós-Graduação e Pesquisa em Administração, 28, 2004, Curitiba. Anais. Curitiba: ANPAD, 2004.

SHAPIRO, Benson P. What the hell is market oriented?. HBR Reprints, 1988.

SILVA, F. A. C.; DAMACENA, C.; MELO, L. M. R. Orientação para o mercado e performance organizacional: um estudo na indústria vinícola do Rio Grande do Sul. In: Congresso Coppead de Administração, 9. 2002, Rio de Janeiro. Anais. Coppead/UFRJ, 2002.

SINGH, Nirmal. Strategic Marketing for Higher Education. In: Tecnia Journal of Management Studies, v. 4, n. 2, October 2009-March 2010.

TAVASSOLI, N. T.; SORESCU, A.; Chandy, R. Employee-based brand equity: Why firms with strong brands pay their executives less. Journal of Marketing Research, 2014.

THOMPSON, J. D. 1967 Organizations in action. New York: McGraw-Hill. 1967.

TSUI, Anne S. A multiple-constituency model of effectiveness: An empirical examination at the human resource subunit level. Administrative science quarterly, p. 458-483, 1990.

TURPIN, Dominique. The CMO Is Dead. Forbes - On Marketing. Disponível em: http:// www.forbes.com/sites/onmarketing/2012/10/03/the-cmo-is-dead/print/. Publicado em: out. 2012. Acessado em: 13/03/2016.

VARADARAJAN, P. Rajan. Marketing's contribution to strategy: the view from a different looking glass. Journal of the Academy of Marketing Science, v. 20, n. 4, p. 335-343, 1992.

VERHOEF, Peter C.; LEEFLANG, Peter S.H.; Understanding the marketing department's influence within the firm. Journal of Marketing, v. 73, p. 14-37, 2009.

WALSH, Gianfranco; BEATTY, Sharon E.; SHIU, Edward MK. The customer-based corporate reputation scale: Replication and short form. Journal of Business Research, v. 62, n. 10, p. 924-930, 2009.

WASHINGTON, Marvin; ZAJAC, Edward J. Status evolution and competition: Theory and evidence. Academy of Management Journal, v. 48, n. 2, p. 282-296, 2005.

WEBSTER, Frederick E., MALTER, Alan J.; GANESAN, Shankar. Can Marketing Regain Its Seat at the Table? Marketing Science Institute Reports. Boston, n. 3, mar. 2003.

WEBSTER, Frederick E.; MALTER, Alan J.; GANESAN, Shankar. The decline and dispersion of marketing competence. MIT Sloan Management Review, v. 46, n. 4, p. 35, 2005.

WHETTEN, David A.; MACKEY, Alison. A social actor conception of organizational identity and its implications for the study of organizational reputation. Business \& Society, v. 41, n. 4, p. 393-414, 2002.

WIND, Yoram; ROBERTSON, Thomas S. Marketing strategy: new directions for theory and research. Journal of Marketing, p. 12-25, 1983. 
A REPUTAÇÃo DO DEPARTAMENTO DE MARKETING NAS INSTITUIÇÕES COMUNITÁRIAS DE ENSINO SUPERIOR BRASILEIRAS E SUA INFLUÊNCIA NA ORIENTAÇÃO PARA O MERCADO

YANAZE, Mitsuru Higuchi. Gestão de comunicação e marketing: avanços e aplicações, São Paulo: Saraiva, 2011.

YU, Kang Yang Trevor; CABLE, Daniel M. Exploring the identity and reputation of departmental groups: whose opinions matter most to their members? Human Resource Management Journal, v. 21, n. 2, p. 105-121, 2011

Recebido em: 30-5-2017

Aprovado em: 29-8-2017

Avaliado pelo sistema double blind review.

Editor: Elmo Tambosi Filho

Disponível em http://mjs.metodista.br/index.php/roc 